\title{
EVALUATION OF RESIDENCE POLICIES IN RELATION TO RESIDENCE /HOME PATTERN / MODEL "CASE STUDY OF SEMNAN CITY"
}

\author{
Abbas Arghan \\ Assistant Prof. in Department of Geography and Urban Planning, Semnan Branch, Islamic Azad \\ University, Semnan, Iran \\ Abbas.arghan@yahoo.com \\ Navid Khajehhoseini \\ Ms Student urban planning at Islamic azad university of Tehran Shomal branch \\ Navid.hosseini39@gmail.com \\ Adineh Meshkinfar \\ Ms Student urban planning at Islamic azad university of Tehran Shomal branch \\ Adineh.meshkinfar@gmail.com \\ Nazanin Moafi \\ Ms Student urban planning at Islamic azad university of Tehran Shomal branch \\ Nazaninmoafi@yahoo.com
}

\begin{abstract}
The policies of securing residence / home, is considered one of the most important problems in our country in recent decode. And thus subject is worth while as a necessity in our country and it is very determining. So in Iran constitutional law (principle 31, 43), it has been regarded as a necessity and exigency to it has been taken into consideration, and government is obliged to provide suitable condition on the background of suitable residence pattern and home securing for all kinds of people in society. This present investigation want to evaluate vital or crucial possibilities, efficiency, availability, meaning perception control and supervision, justice, conformity of from and function of residence policies in Semnan city with regard to home or residence pattern. Surveys result show that government policies in residence can be useful in urban affairs and planning / programming for them in different aspects. In development of city, among others some factors interfere such as or producing cant acts governing in society, come into existence border -living, wearing of old structure establishment of land bank-, control of urban development form, best and optimum use of land and residence pattern.
\end{abstract}

Keywords: residence policies, residence / home pattern, home planning and programming, social participation

\section{INTRODUCTION}

The basic function of residence in addition to its role as a shelter is important economically specially creating engagement and a kind of investment and outcomes increase a place for solace and intensity renewal (the mentalaspeet) and from relation progression (Dalalpour, 2000, 5-7) Having a suitable is a certain social right (Varesi, 2006, 35).

The resident is one of the vitalest man's needs and one of the important causes of development, but the security of shelter is the most difficult among the early needs (Ahari, 1992, 28) Millions households live in different local now that they never realize the comfort environment of the house that is for them and has the necessary equipment. 
There is the settlement problem in all over the world but residence is an aspect of social quiet in developed countries and sit in quality development programs but in developing countries the necessity for its reading is enumerated in the same row of necessity of food and clothing's reading. The residence reading appropriate family's the most cut came specially in tonus and providing isn't got correctly via buying, mortgage and hire, people select suburbia perforce that; following it the other field of cultural and social damages are obtained also modern condition of many of settlements doesn't conform with wishes and gusts people too. Population fast increase and its youth, tending to have a free residence, the movements without program, expensive urban lands, the limitation and shortage of services, constancy and even decrease of agriculture section practitioner following me canization without creating necessary service and industrial new professions, the decrease of possibilities of investment for instruction of literacy and proficiency and creation of suitable profession and enough outcome, the democracy system new-established for invitation of people's communion and activity itself creation and finally tending of paragon and bureaucracy in the chematization of developing countries . In our country the existence of standard residence and also the existence of residence that are adverse with people's willing and needs is undeniable facts which needs the important actions in the residence schematization.

The solution of residence problem with weighty actions by government and with people's communion and with donating to the environment massive goals and the element of constant extension seems to be necessary in schematizations.

\section{THE PROBLEM EXPRESSION}

The using studies is erected on zonal problem and a problem consists of every case that bars in the way of the goal or a desirable result and slow its process (Mirzaie, 1993, 7). It seems so that the residence extension is our goal or as a phrase the desirable condition in our research. But the experience of several decades activity in country residence schematization arena guide us to this fact that not only the scope extension in the residence section of country wasn't occurred but also we were the instance of the out break of problems in this section always. The subject which redounded to many problems and difficulties such as the skew extension of towns, suburbia problems and the mix of economically and population and parity.

The purpose of this paper isn't disburse to all of the out break problems in not booming of settlement but it disburse to one of their most important namely took politics by the government in settlement affair and the survey to amount of urbans social communion in the patterns of town extension too. The government policy can be effective in towns extension from different aspects and It has a part among in the extension of politic and ministerial towns, the economically kindred of the towns of the third world, the production relations that are governor on society and creating of shanty $\mathrm{d}$ welling and suburbia, the central section exhaustion, creation of ground bank and control of towns extension form and the optimum usage of town lands. Nowadays the role of governments in geographic creation space which was forgotten in geographic studies already is the determinant elements and it is focused in all of geographic field, specially the town geography.

\section{THE STUDY PURPOSE}

The main purpose of doing the research is the nomination of evaluation of settlement polices about the Semnan settlement model that the following secondary purpose are discussed with attention to this goal:

1) The survey of amount of consistency and coincidence of programs and adopted policies about settlement with people wishes and needs.

2) The surrey of the relation the Consistency of settlement policies from the aspects of economically, Socially, Cultural and psychology. And the amount of people Social Communion in patterns and the programs of extension and Composition of strategies and the effective 
technique for improvement of settlement Condition and showing directions for practical and usage actions.

The moral model of research is presented in figure 1.

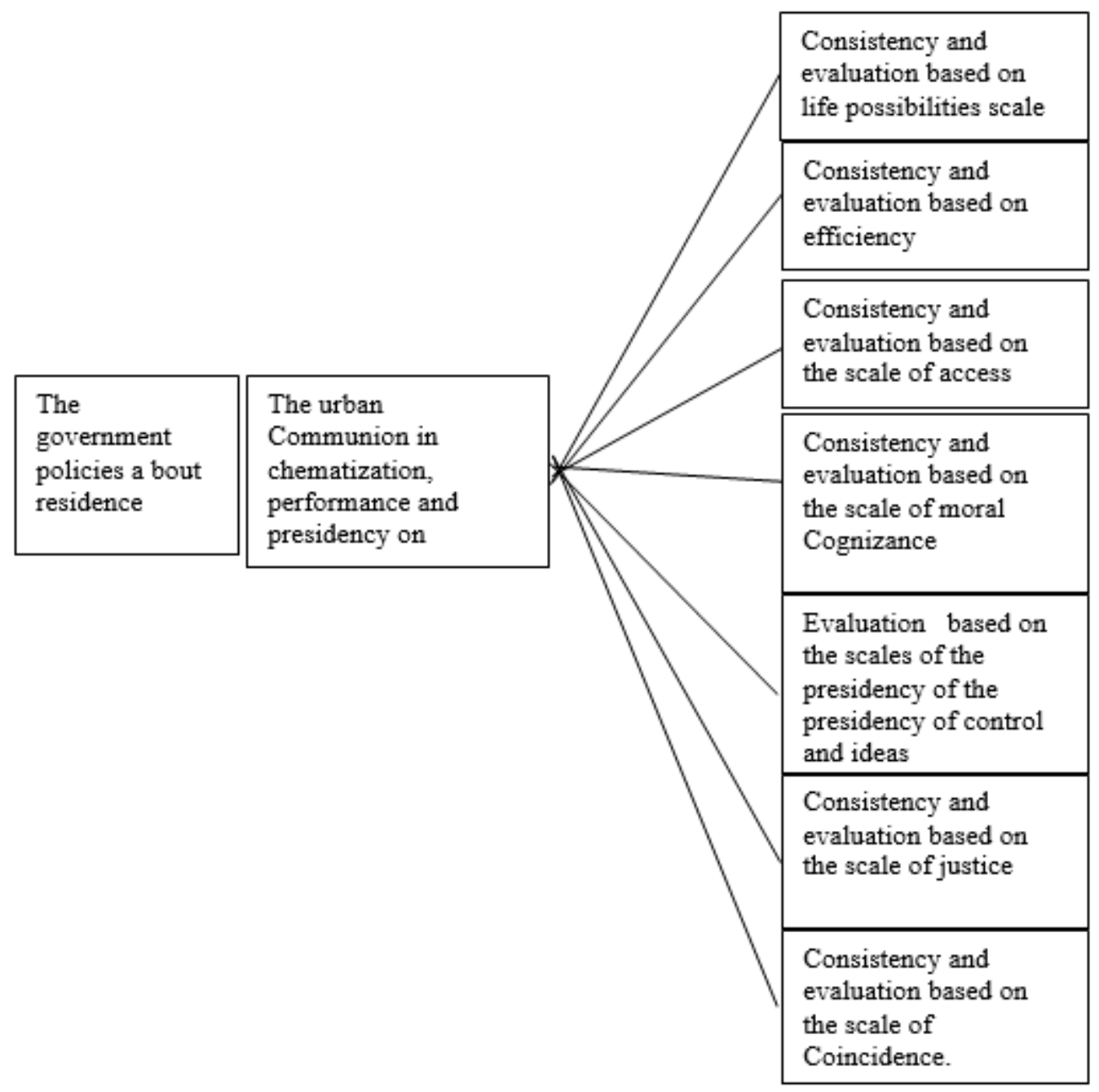

Figure 1. Proposed model structure

\section{THE RESEARCH HYPOTHESIS}

For listing of research hypothesis, first based on the existence Visionary basses and May researches which is done, it is spotted a pre hypothesis similar to beneath:

The Social and all directions Communion of urban sis included as one of the most important reasons of the success of government patterns in settlement chematization now with documentation to the research moral model, the research hypothesis are:

1) It seems that there is a meaningful relation between Consistency of governments programs about settlement and the amount of peoples social Communion.

2) It seems that there is a meaningful relation between Consistency of governments programs and the amount of peoples Communion of realization of social and public justice in town chematization - with focusing on settlement section

The research zone (the totality about the sector where is studied): The location zone of this research is Semnan City. This research is done in the shape of square and any false outside isn't create for performance of the research. The Time Zone of research is 1999 too. Semnan city is the centre of province with the same name that based on existence in formation. This province 
with space equivalent $95815 \mathrm{k} / \mathrm{m}^{2}$ is limited north ward to Mazandaran Golestan, Northern Khorasan provinces, southern to Esfahan and Yazd provinces, Western to Qom and Tehran provinces.

The minimum southern length of Semnan (with the Semnan city Centre) is 52 degrees and 46 minutes and the minimum northern latitude is 34 degrees and 15 minutes and the maximum height of Semnan city from sea surface is 2005 meters and the Time difference of Tehran with Semnan is 7 minutes and 40 Seconds.

This Township for natural position have varied condition as it is limited to Alborz mountain north wade and to desert Southern. The existence of this Condition in climate Variety, geology features and geomorphology and geosoily and also the Variety of Conventions, the pitch of place of residences and the settlement mode are effective in societies and urban place of residences.

The scales of peoples Communion:

- The Vital possibilities:

(Including: suitable environment, security or safety versus the risks, healthy water and healthy air)

\section{- Realization}

Realization or significance and Concept is the degree of clarity and shine where by we can discover the objects and determine their identity, because of the elements Complex that sit in the life society have their special identity and structure. This identity and structure is effected by Cultural, Social, economical geography and Continental elements and each residential unit must show its identity and structure.

\section{- Coincidence}

The Coincidence of person is with work or form Consistency and work .In urbanism, the topics of for Consistency and work is related to public and total space of urban environment that is Compatible for daily Current activities and/or occasionally of resting people in it. The residential unit form should be such that guide the user and create a healthy relation between form and activity than man would have the option of using of the space and the right of changing the space

\section{Access}

is the possibility of transmission and movement of man, objects and in formation from one place to another Availability in the town measure is discussed among its different places and/or among in or out of the city in the urbanism and in measuring of residential unit, access is Construe to all of parts of settlement for all numbers and kin folk as an important element and mans needs. It should be observed two main element about access to accomplish the availability well. One is relief and the other is the economically advantage.

Scheme 1. The diagram of the comparison of residential locale based on the scale of availability.

The evaluation of settlement policies about settlement model supplier: Doctor Abbas Arghan Drawer and depicter:

Engineer Fazlallah Doostmohammadi

- Lookout, presidency control:

Providing, the possibility of tampering, lookout and/or presidency and management of residential spaces is based on need-in other word the scheme of a good residential Complex should provide this possibility for its restrings to tamper based on present and future needs in himself life environment and apply the necessary changes wish and also have the lookout and necessary presidency on his city. 
- The scale of efficiency:

The level of success of doing each work is considering its advantage and disadvantage In other words efficiency. Is the daily scale of advantage and disadvantage? The discussion of efficiency from economically and scientific is that we appoint a reasonable relation between what we invest and what we gain.

Justice:

Is the square distribution of possibilities and costs among the resting persons of a residential Complex? Scheme2: The diagram of the comparison of evaluation of residential locale on the scale of efficiency.

The acts analysis on locales where is studied:

As the same that is said before, the zone that is studied in this research is Semnan City, for survey and evaluation the scales and the criterions of urbanism and also the disable settlement aggregate dots the way of extraneous sample pickup by following:

\section{1) Ladan apartments}

This apartments for geography situation in North West of Semnan city are sit the partition of Negarestan and Tohid squares. In each 500 meter part built four 105 meter unit which have two Category and from both side of northern and southern side have a yard $\left(420 \mathrm{~m}^{2}\right.$ structure and 80 meter yard if we consider 4persons for the number of family's number averagely by attaint 408 residential units in this locale, the number of population estimate probably 1632 persons. The only existence mosque in this locale is inmate mosque and its base. The existence didactic space are Emami girlie school and Sadaf kindergarten, the green space next to the inmate mosque with the sport equipment for children in locale. The special buy centre in the shape of passage. Isn't in this confine and the population of this locale secure their needful from the existence store at the streets and alleys.

The total area of all apartments is equal with $42840 \mathrm{~m}^{2}$.

\section{2) Shaqayeq apartments:}

This apartments are sit at northwest of Semnan, the partition of Shaqayeq and Negarestan squares. They have 10 blocks which has 24 units with old model (240 units) with 127 and 110 and 90 and $45 \mathrm{~m}^{2}$ area and 12 block with 32 units with new model (384 units) with 70 and 90 $\mathrm{m}^{2}$ area and about 300 new units are generating namely park residential units.

If we consider the number of family averagely 4 persons, by attention to 624 existence residential units in this locale the probably number of population is estimate 2496 persons. By view of religious, didactic, sport, sanitary and also the buy Centers, we should say that: the existence of the Ale Aba 5 persons mosque in southern side of Shaqayeq square is the among religious space of scope Confine.

The didactic spaces are: Saadat boy high school and Qods girlie guidance school and Fahmide boy guidance school. The existence of a big park a bout 10 hectares at North West side of Shaqageq apartments with sport equipments that with attention to leakage of space such this with sport equipments in this confine is a population attractive at night full times and holidays. The existence of 115 emergency and Hacrat Roqayeh sanitary Centre at east side of apartments that this sanitary place cover all parts of Golestan. The special buy center as passage isn't in this confine. And the population of this locale secure their need full from the existence store at street and alleys. The total area of all of the apartments is equal to $522 \mathrm{go} \mathrm{m}^{2}$.

\section{3- The DaheFajr apartments:}

This apartments are sit at southern side of powerhouse square at the back of Semnan agriculture office. The new block of Dahefajr apartments have 13 blocks with 8 units and totally are 104 units that each unit has $64 \mathrm{~m}^{2}$ area. Its old apartments have 4 blocks with 8 units totally 32 units and its unit have 75 and go meter. If we consider the number of existence family with attention to 136 existence residential units in locale estimate probably 544 persons. In this Confine isn't any religious space, didactic, sport and sanitary space. The special buy Center as a passage isn't 
in this confine and its population secure their need full from the existence store at the street and environs alleys. The total area of apartments is equal to $9296 \mathrm{~m}^{2}$.

4- Fathalmobin and These apartments are sit at north west of Semnan city, north west side of Negarestan square for geography situation This confine have 12 blocks with 6 units of Fathalmobin and 4 blocks with 24 units of Maskan \& Sharsazi. If we consider the number of existence family averagely 4 persons, with attention to 168 existence residential units in this confine the number of population estimate probably 672 persons. For religious, didactic, sport sanitary space, this confine has this features: The existence of Ahlebeyt mosque is score as a religious space and the only didactic space is Valiasr Primay School. The existence of a big park a bout 10 hectars where is at southern side of Fath AL Mobin and Maskan \& Shahsazi apartments with sport equipment that with attention to the shortage of so big space with sport equipments in this confine is population attractive at nightfall times and holidays. The special buy center as a passage isn't population secure their need full from the existence stores at street and environs alleys. The total area of all of apartments is equal to $14928 \mathrm{~m}^{2}$.

The diagram of the comparison of evaluation of residential locale based on the scale of conformity of from and function.

5) The population ally block of 12 th April:

It is sit in west of Semnan city, southern side the petition of I man Ali square and Shahid Akhlaghi Avenue. In each part 8 block with 24 units is built that have 4 unit with 60 meter which have 4 Categories and it has yard from both side of northern and southern side also it totally $11520 \mathrm{~m}^{2}$ in restructure with the said features. If we consider the number of existence family 4 persons. With attention to 192 existence residential units in this Confine, The number of population estimate probably 768 persons from religious, did active, sport space, we should say that the only existence mosque in this confine is the AL Mahdi mosque. The didactic existence space are Velayat girlie high school. And boy school. The sport spaces is included AL Mahdi Park and Hejab pool. The services and sanitary spaces are included Maskan institution and Shahid Matlabi clinic. The special buy Centre as a passage isn't in this Confine and the population of this locale secure their needful from the existence stores at street and environs alleys. The total area of all of apartment and didactic and spot is equal to 19852 meter.

(Number 5) - The diagram of the comparison of evaluation of residential locale based on the scale of justice.

6- The 400 mechanism population block:

It is sit in the west of Semnan city. Southern Sid the partition of Imam Ali and Imam Hossein square and have 50 blocks with 8 units with old model (400 units) with $90 \mathrm{~m}^{2}$ areas which is a bout $3600 \mathrm{~m}^{2}$ area in restructure. If we consider the number of existence Family 4 persons, with attention to 400 existence residential unit in this con fine estimate probably 1600 persons.

The existence of mosque and also The Amir Almoemenin hospital are the existence possibilities of this confine. The special buy centre as a passage isn't in this con fine and its population secure their need full from the existence stores of street and alleys. The total area of all of the apartment is estimate equal to $52290 \mathrm{~m}^{2}$

7) The komesh Gostar population block (the olden Atash neshani): It is sit at the con fine partition of Kosar and Saedi square. The KomeshGostar population has 12 blocks with 12 units and totally 144 units, which each unit has $90 \mathrm{~m}^{2}$ area it has $12960 \mathrm{~m}^{2}$ in restructure and $1500 \mathrm{~m}^{2}$ is the joint space. If we consider the number of existence family 4/5, with attention to 136 existence residential units in this con fine its number is estimated 544 persons. For didactic, sport, and sanitary space in this confine the 17 Shahrivar Park and the Katam clinic is existence. The special buy centre as passage isn't in this confine and the population of this confine secure their needful from the existence stores at street and environs alleys. The total area of all of apartments is equal $14460 \mathrm{~m}^{2}$ 
(Scheme) The diagram of the comparison of evaluation of residential local based on the scale of control and super vision.

8) The olden Mosalla population block:

It is sit on north of 17 Shahriver Avenue, the partition of Imam Hossein and Saedi square, including 12 blocks with 6 units of FathAl Mobin and 4 blocks with 24 units of Maskan \& Shahrsazi: If we Consider the number of existence Families 4 persons, with attention to 168 existence residential units in this con fine the probably number of population is estimate 672 persons. The existence of the 17 Shahrivar Park and the Khatam clinic and for the services of Melli and Mellat bank are sit in this confine. The special buy centre as a passage isn't in this Confine and the population of this Confine secure their needful from the existence stores of the street and alleys. The total area of all of apartments is equal to $14928 \mathrm{~m}^{2}$.

\section{THE HYPOTHESIS'S EXAMINATION}

First hypothesis: It seems that the government chematization in the shape of native local in the resident affair can help to resident mode reform and provide the field of local participation. We can't develop people but we should provide the field for their development by themselves. In recent years the (expert-hot) research severe ally Consider like horizontal extension and the subject of the role of local people and also the people social participation in the most fields and among government programs in residence affair is sustained in research. In other words in parallelisms of extension of up-down and Current, the standard researches is defied. Iran isn't exempt from this law. Whether this subject is forming with little deferment in our Country. Its time is passed that out wards do research, chematization and per for mince for people. But also this activity should do by people and even peoples direct participation. The statesman's should pay more attention to this sentence and give more cost to people in extension affairs. Listen to all, learn from all, no one knows every things, but every one knows things A view to the present research shows that if the people's participation was more, many of shortages wouldn't be observed.

The existence evaluations shows that although many of population block and apartments units have more possibilities and services and many of factors and fund a metal wishes of people also precept and laws of urbanism, environmental, security, mental are observed. Many of population blocks of this confines also have the minimum possibilities (Fath, Alghadir, Morvarid, Negin, apartments) perhaps it was better than programmers before performance of their observational model beside their specialty consider a compilation of Ideas and people wishes. This subject causes decreasing of cracks and in equality at the city surface and also reaching to social justice that is the most important problems in geography science nowadays.

Based on what is said the schematizations should be steady at the same row of prevention and decreasing the problems and townie difficulties on below tenet and techniques:

- The square securing of existence, mental and social needs of citizens.

- The wise and attendant partake of government from the citizen's participations and its trying for rising the public knowledge level for security of concisely extension and social justice. There for we can conclude that what ever the people participation in affairs and among the residence chematization is more, the government will be more success in its programs and policies. And the fields for decreasing the inequalities would be removed.

\section{THE SECOND HYPOTHESIS}

It seems that there is a meaning full relation between the Consistency of government programs and the amount of people participate on for social and public justice for urban chematization by emphasize on residence section. One of basic bark for extension, is the up-down chematization, the section looking and little attention to general extension and also dissembling the people. The obvious feature of this schematizations is less attention to people and the participation of 
urbanite in affairs that is related to them among the important problem of residence in other words, the movements and their big inabilities in different methods is dissembled. Based on Verner sentence, instead of help to people to develop themselves, we want to be their protector and determinant. Unfortunately many of schematizations and residence extension activities which their purpose is improvement of citizens life, didn't deal to positive results. Nowadays this subject is accepted that one of cause of don't accept the innovation, isn't the citizens unwiring and illiteracy, but also more is innovations not suitable and offering (Verner, 2008, 130) The basic discussed about the extension of one step of subject go upper and reach to a new subject titled (who makes the fact) The theory about the extension constantly is changing.

The discuss of (being more) and (become) and that what role people have in this process is introduced. The subject is here that the researching preferences and extension re are specified by who: Do the local people specify the preferences or out wards or a compilation of both of them? Do experts are for determination of local people or local people are for determinations and the advantages of out wards? (Perat velvizus, 2004, 3). Therefore we said in the second hypothesis we can say such this: (the government programs + people participation $=$ The social and public justice)

\section{DEDUCTION AND SUMMATION}

The usage and observance of the scales and laws of building and urbanism in order in order to forms and the know standards, is prohibited from losing the nationalized assets and finally prevents the chooses and discords or minimize them. $\mathrm{T}$ he below results is obtained from the evaluation of residences extension policies in affair to residence model based on urban extension scales about residential complex and preparation models in Semnan City:

1- The related problems to life and environmental possibilities is not Considered in some of surveyed case, but generally it will create a suitable environment for population life in loge term.

2- The related problems to the scale of perception and sensation in models isn't considered in many of cases (Fath, Alghdir, Morvarid, Negin Units) and some of models are without urban features and without indentity and Couldn't Coordinate it self with the old structure of city and couldn't regain.

3- The related problems to con for misty of from and function seem that sometimes isn't considered.

4- The related Cases to availability were suitable and the availability network almost is designed desirable. But some of residential Complexes such as Fath, Alghadir, Morvarid, and Negin proportion to other complexes and life units have an unsuitable position.

5- About the scale of efficiency, there is a desirable condition but for the reason of don't observance of environmental condition and some of designing and performing costs, this scale act almost weak.

6- The drawing is not so that create the social justice at the distribution of service and the possibilities are not distributed justly a many population.

With paying attention to the top scales, If generally the set of a city and in relation to each other and to a desirable deal and suitable to mans measure and Cultural and natural features and if The designing of residential units which assigned the most Level of city to own self are suitable for scales and the laws of urbanism and are Con forming to people ideas and participation, can admit that the environment is designed for man's needs.

\section{THE OFFERS}

- More chematization a bout adjusting more the residence extension program with the laws and manual of urbanism.

- Creating the suitable organization structure and ministerial and researching bendable for doing participation ally researches. 
The Turkish Online Journal of Design, Art and Communication - TOJDAC July 2016 Special Edition

- Instruction and using of comparative studying model method instead of imitative model in residence securing.

- The exercise of participation by organizations and its personnel herewith people.

- emphasis on quality results instead of identity future and early out put in researching activities about residence.

- Emphasis on pedestal people researches instead of emphasis on pedestal production researches and pedestal crop.

- support the unstated, cooperation ally and people organizations in the residence affair.

- Emphasis on systematic theory in schematizations.

- Support and develop the persuasive by laws for researchers in the field of usage and participation researches in the residence affair and....

\section{REFERENCES}

Ahari, Z, minimum residence, the centre of the researches of structure and residence, Tehran, second edition, Bahman 1992.

Varesi, H, An analysis of the problems of residence of Isfahan city (PHD thesis), The guidance professor, Isfahan university, 2000

Mirzaieaharanjani, H, Using researches, the management science, year 5, number 18, 1992.

Shekoyie, H, The new viewpoints in urban geography, Samt publications, 2000.

Rezvani, A, The polar relations of city and village with emphasis on Iran, payam nour university, 1995.

Housyar, H, The view points, the effective factors and elements in physical extension of the towns of Iran, The Roshd quarterly of geography instruction, sixteenth term, number3, 2005.

Varesi, H, The governor problems on residence section in Iran, the quarterly Maskan \& Enqelab, number 112, 2005.

Rahmani, A, the 15 years function of resident section in the first, second and third programs of economically extension (1989-2003) the monthly periodical politic economically in formation September-October 2003, number 217-218

The program and budget organization of Semnan: economically report 1374 year, April 1997.

Verner, R., participation extension of agriculture innovations, Tehran, agriculture Combat ministry, The centre of researches and survey of villager problems, 2002.

Parat L, the selection of researching method, Tehran, agriculture Combat ministry, The centre of researches and survey of villager problems, 2003.

Dalalpour, M, the resident chematization, Samt publications, 2000. 